\title{
ANÁLISES ISOENZIMÁTICAS EM SOMACLONES DE MORANGUEIRO (Fragaria x ananassa DUCH.) cv. VILA NOVA
}

\author{
ISOZYMIC ANALYSES OF SOMACLONES FROM STRAWBERRY \\ (Fragaria x ananassa DUCH.) cv. VILA NOVA
}

\author{
Rejane Flores $^{1}$ Beatriz Gomes Rocha ${ }^{2}$ José Antonio Peters ${ }^{3}$ \\ Eliane Augustin ${ }^{4}$ Gerson Renan de Luces Fortes ${ }^{5}$
}

\section{RESUMO}

Análises isoenzimáticas foram utilizadas para investigar variações bioquímicas em somaclones de morangueiro cultivar Vila Nova, obtidos a partir de calos. Utilizaram-se como amostras folhas jovens de plantas durante a multiplicação in vitro e após a aclimatização em casa de vegetação. Os sistemas enzimáticos utilizados para a análise dos clones foram fosfatase ácida e esterase (pH 6,5 e 8,3). Durante o cultivo in vitro, dois padrões de fosfatase ácida foram detectados entre os regenerantes; já para a esterase, todos os genótipos exibiram o mesmo padrão de bandas. Em casa de vegetação, foram encontrados três padrões de bandas distintos de fosfatase ácida. Não foram verificadas alterações quanto ao número e posição das bandas de esterase em $\mathrm{pH}$ 6,5, enquanto que para a esterase em $\mathrm{pH} 8,3$ observou-se polimorfismo entre os clones. Ambos os sistemas enzimáticos mostraram-se influenciados pelas condições de crescimento (in vitro $e$ in vivo) e pelos estádios de desenvolvimento das plantas.

Palavras-chave: morangueiro, cultivo in vitro, variação somaclonal, esterase, fosfatase ácida.

\section{SUMMARY}

Isozymic analyses were used to investigate biochemical variations of somaclones from strawberry cultivar Vila Nova, obtained starting from calli. Analyses were performed using young leaves collected from plants during the in vitro multiplication and afther aclimatation at greenhouse. The enzyme systems used for the analysis of the clones consisted of acid phosphatase and esterase (pH 6.5 and 8.3). During the in vitro culture, two patterns of acid phosphatase were detected among the regenerants, however for the esterase all the genotypes exhibited the same pattern of bands. At greenhouse, were found three patterns of bands different for acid phosphatase. Alterations were not verified in relation to the number and band position for esterase ( $p H$ 6.5), while, for esterase ( $p H$ 8.3) polymorphism was observed among the clones. Both enzyme systems were influenced by the growth condiction (in vitro and in vivo) and by the developing stage of the plants

Key words: strawberry, in vitro culture, somaclonal variation, esterase, acid phosphatase.

\section{INTRODUÇÃO}

Marcadores bioquímicos, como as isoenzimas possibilitam detectar alterações metabólicas que ocorrem durante o crescimento, desenvolvimento e diferenciação da planta (PRAMANIK $\boldsymbol{e t} \boldsymbol{a l}$. 1996). Outras contribuições das isoenzimas para o melhoramento genético vegetal incluem a identificação de cultivares, avaliação de germoplama e uso como marcadores genéticos (TANKSLEY \& ORTON, 1983), possibilitando a seleção precoce de genótipos superiores. Em morangueiro, elas têm sido utilizadas para caracterização de cultivares (BRINGHURST et al., 1981; ROCHA et al. 1998), estudo da herança de sistemas enzimáticos (ARULSEKAR $\boldsymbol{e t} \boldsymbol{a l}$. 1981), análise da variabilidade enzimática em espécies do gênero Fragaria (ARULSEKAR \& BRINGHURST, 1983) e na detecção de alterações enzimáticas em somaclones (NEHRA et al., 1992; DAMIANO et al., 1995).

Neste trabalho, dois sistemas enzimáticos foram utilizados para estudar a variabilidade entre somaclones de morangueiro cv. Vila Nova durante o cultivo in vitro e em casa de vegetação.

\section{MATERIAL E MÉTODOS}

O trabalho foi desenvolvido no Laboratório de Cultura de Tecidos Vegetais e no Laboratório de Eletroforese da Empresa Brasileira de Pesquisa Agropecuária de Clima Temperado (Embrapa Clima Temperado), Pelotas, RS.

O meio de cultura básico utilizado foi o MS (MURASHIGE \& SKOOG, 1962), com 30g $\ell^{-1}$

\footnotetext{
${ }^{1}$ Biólogo, Mestre em Ciências pela Universidade Federal de Pelotas (UFPel). Rua Floriano Peixoto, 979, 97400-000, São Pedro do Sul, RS. Autor para correspondência.

${ }^{2}$ Engenheiro Agrônomo, Doutor na Universidade Federal de Pelotas (UFPel), Pelotas, RS

${ }^{3}$ Engenheiro Agrônomo, Professor, Doutor, Instituto de Biologia, UFPel.

${ }^{4}$ Engenheiro Agrônomo, Pesquisador, Doutor, Embrapa Clima Temperado, Pelotas, RS.

${ }^{5}$ Engenheiro Agrônomo, Pesquisador, Doutor, Embrapa Clima Temperado, Pelotas, RS.
} Recebido para publicação em 14.05.99. Aprovado em 12.04.00 
de sacarose, $100 \mathrm{mg}^{-1}$ de mio-inositol e $6 \mathrm{~g} \ell^{-1}$ de ágar. $\mathrm{O}$ pH foi ajustado para 5,9.

Para a indução de calos, discos foliares de morangueiro cv. Vila Nova foram cultivados no meio básico, contendo $5 \mu \mathrm{M}$ de 2,4-D (ácido 2,4 diclorofenoxiacético) e $5 \mu \mathrm{M}$ de BAP (6benzilaminopurina). $\mathrm{O}$ material foi incubado no escuro, em sala de crescimento, com temperatura de $25 \pm 2{ }^{\circ} \mathrm{C}$ por um período de três semanas. Posteriormente, os calos foram mantidos em sala de crescimento com fotoperíodo de 16 horas de luz e radiação de $19 \mu \mathrm{mol} . \mathrm{m}^{-2} \cdot \mathrm{s}^{-1}$. Após quatro semanas de cultivo, os calos foram transferidos para meios de regeneração contendo $5 \mu \mathrm{M}$ BAP, $10 \mu \mathrm{M}$ BAP, $15 \mu \mathrm{M}$ de TDZ (thidiazuron) e $10 \mu \mathrm{M}$ de TDZ $+500 \mathrm{mg}^{-1}$ de caseína hidrolizada $(\mathrm{CH})$. A cultura foi mantida em sala de crescimento com fotoperíodo de 16 horas, radiação de $19 \mu \mathrm{mol} . \mathrm{m}^{-2} . \mathrm{s}^{-1}$ e temperatura de $25 \pm 2^{\circ} \mathrm{C}$ durante o restante do cultivo in vitro.

As brotações regeneradas foram individualizadas e denominadas de clones. Os clones representados pela letra A foram provenientes do meio com $5 \mu \mathrm{M}$ de BAP. Os clones com letras B foram regenerados em meio acrescido de $10 \mu \mathrm{M}$ de BAP. A letra $\mathrm{C}$ representa o meio contendo $15 \mu \mathrm{M}$ de TDZ e os clones com letra $\mathrm{D}$ são provenientes do meio com $10 \mu \mathrm{M}$ de TDZ + 500mg $\ell^{-1}$ de $\mathrm{CH}$. Brotações regeneradas diretamente a partir de meristemas, sem passar pelo cultivo de calos, foram multiplicadas no mesmo meio e representadas pela letra $\mathrm{E}$.

Os clones foram multiplicados no meio MS com nitrogênio reduzido a $3 / 4,40 \mathrm{~g} \ell^{-1}$ de sacarose e acrescido de $0,05 \mu \mathrm{M}$ de ANA (ácido $\alpha$ naftalenoacético), $0,4 \mu \mathrm{M}$ de $\mathrm{AG}_{3}$ e $2,2 \mu \mathrm{M}$ de BAP. Posteriormente, as plantas foram enraizadas em meio MS isento de reguladores de crescimento e aclimatizadas em casa de vegetação.

Os sistemas isoenzimáticos utilizados na análise dos clones de morangueiro foram fosfatase ácida (FAC) e esterase (EST). Como amostras, utilizaram-se folhas novas, as quais foram retiradas quinze dias após o subcultivo em meio de multiplicação e 30 dias do plantio em casa de vegetação. Foi adotada a técnica de eletroforese horizontal em gel de poliacrilamida, utilizando o sistema de tampão descontínuo, descrito por SCANDALIOS (1969) em pH 8,3, com a concentração $6 \%$ para ambos os sistemas. No preparo dos géis da FAC, foi acrescentado $2 \%$ de polietileno glicol. Para o sistema EST, também foi utilizado o tampão contínuo tris-citrato (pH 6,5), segundo NICHOLS \& RUDDLE (1973), na concentração de $5 \%$ de poliacrilamida.

Os géis consistiram de $100 \mathrm{~m} \ell$ do tampão do gel com $5,7 \mathrm{~g}$ de acrilamida e $0,3 \mathrm{~g}$ de bisacrilamida (EST pH 8,3 e FAC) ou 4,75g de acrila- mida e 0,25 de bis-acrilamida (EST pH 6,5), acrescidos de $0,10 \mathrm{~m} \ell$ de $\mathrm{N}, \mathrm{N}, \mathrm{N}^{\prime}, \mathrm{N}^{\prime}$ - tetrametilenodiamina e $1 \mathrm{~m} \ell$ de persulfato de amônio a $10 \%$. Foram maceradas dez mg de cada amostra com $10 \mu \ell$ do tampão do gel, na diluição de $1: 1$, acrescido de $0,15 \%$ de 2mercaptoetanol e $2,5 \mathrm{mg}$ de polivinilpolipirrolidona. As migrações foram feitas aplicando-se uma diferença de potencial de $10 \mathrm{v} / \mathrm{cm}$ linear. Posteriormente, os eletroforegramas foram imersos em tampão de coloração específico para cada sistema com $20 \%$ de acetona, durante um período de 20 minutos.

Para a revelação dos géis, foram utilizados os sistemas de coloração descritos por SCANDALIOS (1969), no escuro e a $37^{\circ} \mathrm{C}$ durante, aproximadamente, 15 horas. Após a revelação, os géis foram colocados em fixador com água destilada, metanol e ácido acético na proporção de 5:5:1.

O cálculo da mobilidade relativa (MR) para os sistemas enzimáticos foi realizado registrando as distâncias migradas pelas bandas a partir do ponto de aplicação e dividindo-as pela medida de uma banda tomada como padrão, sendo comum a todos os clones.

A estimativa da similaridade genética entre os clones de morangueiro foi realizada através do coeficiente de associação, utilizando o índice de Jaccard (CRISCI \& ARMENGOL, 1983). A análise de grupamento dos clones foi feita pelo método da média aritmética não ponderada (UPGMA) analisada através do programa NTSYS - pc (ROHLF, 1989).

\section{RESULTADOS E DISCUSSÃO}

As análises de todas as amostras coletadas 15 dias após o subcultivo das plantas em meio de multiplicação apresentaram seis bandas anódicas de FAC, com mobilidades relativas de 1,$50 ; 1,35 ; 1,25$; 1,$12 ; 1,00$ e 0,88 (Padrão A). Nos clones A2, A3, A7, A13, A18, B2 e B5, foi detectada, além dessas, uma banda com MR de 0,72 (Padrão B) (Figura 1A). Os clones foram classificados em dois grupos de acordo com as diferenças observadas (Tabela 1). Verificou-se que a maioria dos clones $(68 \%)$ apresentaram o mesmo padrão de bandas da testemunha (E) (Padrão A) e 32\% apresentaram o padrão B, principalmente os provenientes do meio acrescido de $5 \mu \mathrm{M}$ de BAP.

DAMIANO et al. (1995), estudando organogênese a partir de calos e suspensões celulares em cinco cultivares de morangueiro, também observaram diferenças nos padrões da FAC, peroxidase e glutamato desidrogenase, as quais foram detectadas entre as cultivares, sendo menos freqüentemente entre os regenerantes de cada cultivar.

Não foram verificadas alterações quanto ao número e posição das bandas de EST em todas as amostras coletadas in vitro. O sistema EST (pH 6,5) 


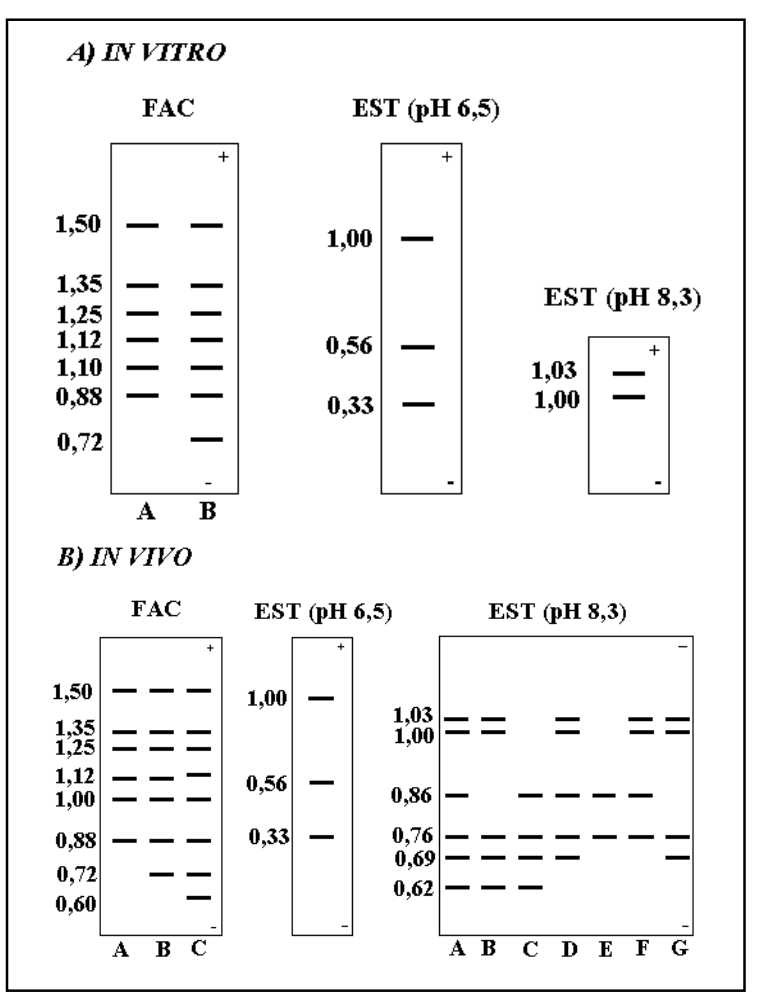

Figura 1 - Padrões isoenzimáticos da fosfatase ácida e esterase (pH 6,5 e 8,3) em clones de morangueiro da cultivar Vila Nova provenientes do cultivo in vitro e da casa de vegetação (in vivo). Pelotas, RS, 1999.

apresentou três bandas estáveis e nítidas com MR de 0,33; 0,56 e 1,00. Os zimogramas da EST ( $\mathrm{pH} \mathrm{8,3)}$ apresentaram duas bandas com MR de 1,00 e 1,03 (Figura 1-A). Embora tenha sido verificada a presença de outras bandas, não foi possível considerá-las na análise, pois devido à alta atividade da esterase durante o cultivo in vitro, não apresentaram nitidez.

Nas análises da FAC nas plantas, após a aclimatização e transferência para a casa de vegetação, foram encontrados três padrões distintos, com seis a oito bandas (Figura 1-B). Diferente do ambiente in vitro, verificou-se que $59 \%$ dos clones (in-

Tabela 1 - Classificação de clones de morangueiro cultivar Vila Nova, segundo as diferenças encontradas nos padrões eletroforéticos da fosfatase ácida , durante o cultivo in vitro. Pelotas, RS, 1999.

\begin{tabular}{|c|c|c|c|}
\hline PADRÕES & CLONES & $\begin{array}{l}\text { MOBILIDADES } \\
\text { RELATIVAS }\end{array}$ & $\begin{array}{c}\text { FREQÜÊNCIAS } \\
(\%)\end{array}$ \\
\hline A & $\begin{array}{l}\text { B7; B8; B10; B11; C1; C6; C7; } \\
\text { C8; C9; C12; C144; C17; C19; D15: } \\
\text { E }\end{array}$ & $\begin{array}{l}1,50 ; 1,35 ; 1,25 ; 1,12 ; 1,00 ; \\
0,88\end{array}$ & 68 \\
\hline $\mathrm{B}$ & A2; A3; A7; A13; A18; B2: B5 & $\begin{array}{l}1,50 ; 1,35 ; 1,25 ; 1,12 ; 1,00 \\
0,88 ; 0,72\end{array}$ & 32 \\
\hline
\end{tabular}

cluindo o E) apresentaram o padrão B (Tabela 2), indicando que o estágio de desenvolvimento das plantas afeta os padrões isoenzimáticos.

Nessas plantas, também não se detectou polimorfismo para a EST ( $\mathrm{pH} 6,5)$, pois todos os clones apresentaram três bandas com MR de 0,33; 0,56 e 1,00 (Figura 1-B).

$\mathrm{O}$ decréscimo na atividade da EST $(\mathrm{pH}$ 8,3) nas plantas provenientes da casa de vegetação, permitiu a visualização de diversas bandas polimórficas. Observaram-se sete padrões eletroforéticos para esse sistema, com duas a seis isoenzimas (Figura 1-B). As diferenças observadas permitiram classificar os clones em sete grupos (Tabela 3). A maioria dos clones (50\%) apresentou o mesmo padrão do clone $\mathrm{E}$ (Padrão $\mathrm{A}$ ), no qual se detectou o maior número de bandas. Os clones A3, A18, C6 e D15 apresentaram padrões exclusivos, denominados de B, C, E e F, respectivamente. As bandas com MR de 1,03 e 1,00, presentes nas plantas durante o cultivo in vitro, não foram detectadas nos clones A18 e C6 (Tabela 3).

Em macieira, análises isoenzimáticas têm sido úteis para detectar variabilidade entre os somaclones (MARTELLI et al., 1993). No entanto, de forma semelhante aos resultados obtidos com a cv. Vila Nova, os padrões isoenzimáticos foram bastante influenciados pelas condições de crescimento do material, uma vez que amostras de folhas dos mesmos clones de macieira, crescidos in vitro e in vivo, mostraram diferentes padrões de bandeamento (MARTELLI et al., 1993).

Os padrões de isoenzimas e a intensidade das bandas são específicos para órgãos ou tecidos e para os estádios de desenvolvimento e maturidade. O estádio de desenvolvimento em que aparecem ou desaparecem refletem a ativação ou repressão dos genes que codificam essas isoenzimas (SCANDALIOS, 1974). Essas alterações são refletidas nos padrões de bandas, como foram verificados nos diversos clones.

ROCHA et al. (1998), estudando cultivares de morangueiro sob diferentes condições ambientais (in vitro, casa de vegetação, telado e campo), não observaram diferenças em padrões isoenzimáticos da FAC. Em todas as cultivares (inclusive KonvoyCascata e Lassen), os autores detectaram seis bandas monomórficas, que também foram verificadas na cv. Vila Nova. Essa similarida- 
Tabela 2 - Classificação de clones de morangueiro cultivar Vila Nova, segundo as diferenças encontradas nos padrões eletroforéticos da fosfatase ácida, quando cultivados em casa de vegetação. Pelotas, RS, 1999

\begin{tabular}{|c|c|c|c|}
\hline PADRÕES & CLONES & MOBILIDADES RELATIVAS & $\begin{array}{c}\text { FREQÜÊNCIAS } \\
(\%)\end{array}$ \\
\hline A & $\mathrm{A} 18 ; \mathrm{C} 1 ; \mathrm{C} 17 ; \mathrm{C} 19$ & 1,$50 ; 1,35 ; 1,25 ; 1,12 ; 1,00 ; 0,88$ & 18 \\
\hline $\mathrm{B}$ & $\begin{array}{l}\text { A } 2 ; \mathrm{A} 3 ; \mathrm{A} 7 ; \mathrm{A} 13 ; \mathrm{B} 2 ; \mathrm{B} 7 ; \mathrm{B} 8 \\
\mathrm{~B} 10 ; \mathrm{B} 11 ; \mathrm{C} 7 ; \mathrm{C} 12 ; \mathrm{C} 14 ; \mathrm{E}\end{array}$ & $\begin{array}{l}1,50 ; 1,35 ; 1,25 ; 1,12 ; 1,00 ; 0,88 ; \\
0,72\end{array}$ & 59 \\
\hline $\mathrm{C}$ & $\mathrm{B} 5 ; \mathrm{C} 6 ; \mathrm{C} 8 ; \mathrm{C} 9 ; \mathrm{D} 15$ & $\begin{array}{l}1,50 ; 1,35 ; 1,25 ; 1,12 ; 1,00 ; 0,88 \\
0,72 ; 0,60\end{array}$ & 23 \\
\hline
\end{tabular}

do em quatro subgrupos. Nota-se, no segundo subgrupo, que quatro clones (B7, B8, B10 e B11) provenientes do meio de regeneração, contendo $10 \mu \mathrm{M}$ de BAP, apresentaram similaridade máxima com o clone testemunha (E). O segundo grupo foi constituído apenas

de pode ser devida à genealogia das cultivares, pois a Vila Nova é proveniente do cruzamento entre Konvoy-Cascata e Lassen.

Estudos demostraram que, durante a morfogênese de Plantago ovata (planta medicinal), apareceram duas novas bandas, as quais estavam ausentes no controle e nas plantas já regeneradas (PRAMANIK $\boldsymbol{e t} \boldsymbol{a l}, 1996)$. Os autores salientam que estas duas novas formas moleculares da esterase resultam da ativação de genes essenciais durante o processo de multiplicação.

Sabe-se que em experimentos de variação somaclonal baseados em isoenzimas, os padrões devem ser comparados não apenas pela presença ou ausência de bandas, mas pela quantidade de proteína por banda. Neste trabalho, em ambos os sistemas estudados, registraram-se alterações na intensidade das bandas, porém não foram repetitivas, que podem ser decorrentes do estágio de desenvolvimento das folhas analisadas.

Análises isoenzimáticas em somaclones de morangueiro, cv. Redcoat, não demonstraram alterações qualitativas nos padrões de leucina aminopeptidase (LAP), fosfoglucomutase (PGM), fosfoglucose isomerase (PGI) e esterase (EST). No entanto, foram verificadas alterações na intensidade das bandas da EST que, à semelhança do observado neste trabalho, não foram repetitivas (NEHRA $\boldsymbol{e t}$ al, 1992).

Considerando-se os 22 clones e os sistemas enzimáticos da FAC e EST em pH 8,3, estimou-se a similaridade genética entre os clones. Não foi considerado, neste estudo, a EST em $\mathrm{pH} 6,5$, pois não apresentou polimorfismo.

Pela análise de agrupamento dos clones, foi possível classificar os mesmos em dois grupos. O primeiro, foi constituído pela maioria dos clones e dividi- pelos clones A18 e C6, os quais se encontraram mais distantes dos demais (Figura 2).

Os métodos bioquímicos, como a análise de isoenzimas, são amplamente utilizados para detectar polimorfismo genético em várias espécies. Entretanto, a principal limitação dessa técnica é o limitado polimorfismo que elas são capazes de detectar entre populações muito próximas (CROCHEMORE, 1998), o que dificultou a análise dos clones obtidos no presente trabalho. Análises de isoenzimas detectam apenas alterações genéticas que modificam a estrutura (ALFENAS et al., 1991) e/ou a carga elétrica das proteínas, em regiões do DNA que correspondem a um número limitado de genes que codificam para as enzimas (TORGGLER $\boldsymbol{e t} \boldsymbol{a l}$., 1995). Portanto, não cobrem todo o genoma. Por outro lado, estudos baseados no DNA possibilitam a detecção de alterações genéticas, em regiões codificadoras ou não codificadoras (TORGGLER $\boldsymbol{e t} \boldsymbol{a l}$., 1995), em qualquer estádio de desenvolvimento da planta e independentemente dos efeitos do meio ambiente. Dessa forma, estudos neste sentido devem ser realizados com o intuito de confirmar e caracterizar possíveis alterações genéticas nos diversos clones obtidos neste trabalho.

\section{CONCLUSÕES}

O estádio de desenvolvimento das plantas afeta os padrões isoenzimáticos.

Tabela 3 - Classificação de clones de morangueiro cultivar Vila Nova, segundo as diferenças encontradas nos padrões eletroforéticos da esterase ( $\mathrm{pH} \mathrm{8,3),} \mathrm{quando} \mathrm{cultivados} \mathrm{em} \mathrm{casa} \mathrm{de} \mathrm{ve-}$ getação. Pelotas, RS, 1999

\begin{tabular}{cllc}
\hline \multirow{2}{*}{ PADRÕES } & \multicolumn{1}{c}{ CLONES } & MOBILIDADES RELATIVAS & FREQÜÊNCIAS (\%) \\
\hline & A2; A7; A13; B2; B5; B7; & 1,$03 ; 1,00 ; 0,86 ; 0,76 ; 0,69 ; 0,62$ & 50 \\
A & B8; B10; B11; C1; E & & \\
& A3 & 1,$03 ; 1,00 ; 0,76 ; 0,69 ; 0,62$ & 4,4 \\
B & A18 & 0,$86 ; 0,76 ; 0,69 ; 0,62$ & 4,5 \\
C & C8; C9; C14; C17; C19 & 1,$03 ; 1,00 ; 0,86 ; 0,76 ; 0,69$ & 23 \\
D & C6 & 0,$86 ; 0,76$ & 4,5 \\
E & D15 & 1,$03 ; 1,00 ; 0,86 ; 0,76$ & 4,5 \\
F & C7;C12 & 1,$03 ; 1,00 ; 0,76 ; 0,69$ & 9 \\
\hline
\end{tabular}




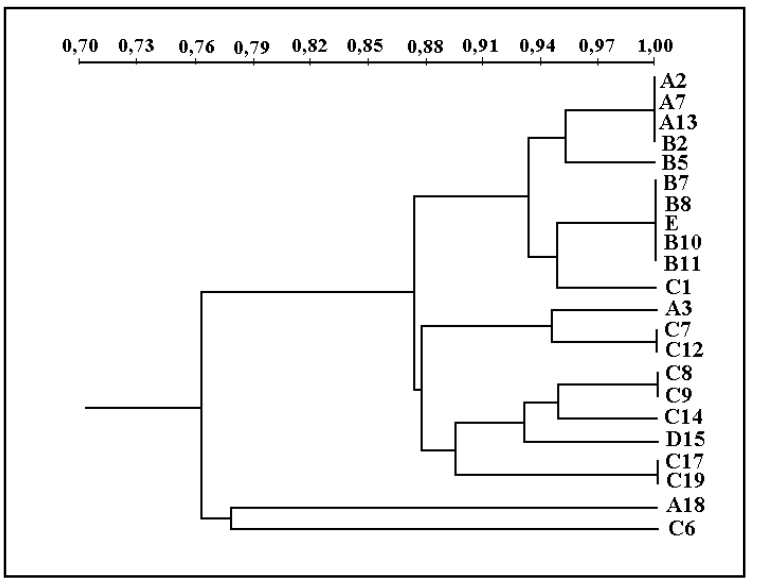

Figura 2 - Dendograma de 22 clones de morangueiro da cultivar Vila Nova, baseado na similaridade genética, através dos sistemas enzimáticos da fosfatase ácida e esterase (pH 8,3), pelo método de UPGMA. Pelotas, RS, 1999.

A análise de isoenzimas de fosfatase ácida e de esterase $(\mathrm{pH} 8,3)$ possibilitam a identificação de plantas variantes regeneradas a partir de calos.

\section{REFERÊNCIAS BIBLIOGRÁFICAS}

ALFENAS, A.C., PETERS, I.; BRUNE, W., et al. Eletroforese de proteínas e isoenzimas de fungos e essências florestais. Viçosa : UFV, 1991.

ARULSEKAR, S., BRINGHURST, R. S., VOTH, V. Inheritance of PGI and LAP isozymes in octoploid cultivated strawberries. Journal of American Society Science, v.106, n.5, p.679-683, 1981 .

ARULSEKAR, S., BRINGHURST, R.S. Strawberry. In TANKSLEY, S.D., ORTON, T.J. (Ed.) Isozymes in plant genetics and breeding. Amsterdam : Elsevier Science Publishers, 1983. p.391-400.

BRINGHURST, R.S., ARULSEKAR, S., HANCOCK, et al. Electrophoretic characterization os strawberry cultivars. Journal of American Society of Horticultural Science., v.106, n.5, p.684-687, 1981.

CROCHEMORE, M.L. Variabilidade genética da alfafa: marcadores agromorfológicos e moleculares. Londrina: IAPAR, 1998. (Boletim Técnico, n. 58).

DAMIANO, C., ASCARELLI, A., FRATTARELLI, A., $\boldsymbol{e} \boldsymbol{t} \boldsymbol{a}$.
Adventitious regeneration and genetic variability in strawberry. Acta Horti culturae, n.392, p.107-114, 1995.

MARTELLI, G., GRECO, I., MEZZETTI, B., et al. Isozymic analysis of somaclonal variation among regenerants from apple rootstock leaf tissue. Acta Horticulturae, v.336, p.381-387, 1993.

MURASHIGE, T., SKOOG, F. A revised medium for rapid growth and bioassays with tobacco tissue cultures. Physiologia Plantarum., v.15, p.473-497, 1962.

NEHRA, N.S., KARTHA, K.K., STUSHNOFF, C., et al. The influence of plant growth regulator concentrations and callus age on somaclonal variation in callus culture regenerants of strawberry Plant Cell, Tissue and Organ Culture, v.29, p.257-268, 1992.

NICHOLS, E.A., RUDDLE, F. Review of enzime polymorphism, linkage and electrophoretic conditions for mouse and somatic cell hybrids in starch gels. Journal Histochem Cytochem, v.21, n.12, p.1066-1081, 1973.

PRAMANIK, S., RAYCHAUDHURI, S.S., CHAKRABORTY, S. Changes in esterase and superoxide dismutase isozymes during in vitro morphogenesis in Plantago ovata Forssk. Plant Cell Tissue and Organ Culture, v.44, p.123-127, 1996.

ROCHA, B.H.G., NAKASU, B.H., AUGUSTIN, E. Caracterização isoenzimática de morangueiro (Fragaria x ananassa Duch.) sob diferentes condições ambientais. Agropecuária Clima Temperado, v.1, n.2, p.171-176, 1998.

ROHLF, F.J. NTSYS-pc numerical taxonomy and multivariate analysis system. Version 1.50. New : York: Exater, 1989. 191p.

SCANDALIOS, J.G. Genetic control of multiple molecular forms of enzymes in plants: a review. Biochemical Genetics, New York, v.3, p.37-79, 1969.

SCANDALIOS, J.G. Isozymes in development and differentiation. Annual Review of plant Physiology, v.25, p.225-258, 1974.

TANKSLEY, S.D., ORTON, T.J. Isozymes in plant genetics and breeding. Amsterdam : Elsevier Science Publishers, 1983.

TORGGLER, M.G.F., CONTEL, E.P.B., TORGGLER, S.P. Isoenzimas: variabilidade genética em plantas. Ribeirão Preto: SBG, 1995.

Ciência Rural, v. 30, n. 6, 2000. 